\title{
The Shear Bearing Capacity Mechanism Analysis of Steel Pipe Steel Reinforced Concrete Composite Column
}

\author{
Bing WANGa ${ }^{\mathrm{a}}$, Xiao LIU ${ }^{\mathrm{b},{ }^{*}}$, Tian-Cheng XUc \\ School of Architectural and Civil Engineering, Shenyang University, Shenyang, 110044, China \\ aliuxiao19740701@sina.com, b1643274246@qq.com, c15702475009@163.com \\ ${ }^{*}$ Corresponding author
}

\begin{abstract}
Keywords: Steel Pipe Steel Reinforced Concrete Composite Column, Shear Bearing Capacity, Mechanism Analysis.
\end{abstract}

\begin{abstract}
In this paper, the ABAQUS finite element model is established. using the stress distribution of the components during the calculation analysis, we analyzed the working mechanism of steel pipe steel reinforced concrete composite column shear components, it is concluded that $\mathrm{P}$ $\mathrm{U}$ curve of the shear component is divided into three stages: elastic stage, elastic-plastic stage and plastic stage, mainly due to the effect of the increase of the zone of both the tension zone and the compression one. Axial compression ratio has much effect on the plastic stage of the curve , especially under the condition of high axial compression ratio, there exists the decline in the period of the plastic stage.
\end{abstract}

\section{Introduction}

In recent years, the study on the shear capacity of steel tube steel reinforced concrete is mature. the research on axial compression, bias , compression bending, bending performance of round steel pipe steel reinforced concrete columns built-in i-steel is common [1-3], but the research on the mechanism of steel pipe steel reinforced concrete shear has not been reported and steel tube steel reinforced concrete is pouring concrete in steel tube, combining concrete and steel .The internal concrete can enhance the strength and stability of the steel tube. Inserting i-steel inside the component can make it continue to play a strong load-bearing role after the loss of bearing capacity of the outside steel pipe. At the same time, because of the existence of core concrete, it delays the internal steel bone expiry time, which gives people plenty of time to escape the rescue, thereby reducing property and life loss [4-7].

In this paper, the research on the bending shear and the compression bending shear performance of round steel pipe steel reinforced concrete columns built in i-steel is also very meaningful. This chapter, the shear mechanism is studied by using finite element analysis software ABAQUS.

\section{The Mechanism Analysis of Steel Tube Steel Reinforced Concrete}

The finite element model adopted in this article can better simulate the stress state and mechanical performance of steel pipe steel reinforced concrete composite column shear components Now we use the above results to analyze working mechanism of steel reinforced concrete filled steel tube column shear components. Fig. 1 shows the stress state before and after load of steel tube steel reinforced concrete shear components.

We can find that the lower part of the steel tube moves towards outside slightly.It illustrates that the core concrete is in a state of three-way force,because of the hoop constraint function exerted by the steel tube. And brittle failure does not occur, which improves the strength and plasticity of composite components. Regardless of adjustment in the the above parameters of the parameter, shape change of $\mathrm{P}$ - U curve of shear component is not obvious. Fig. 2 shows the typical P-U curve of the steel tube steel reinforced concrete. According to the shape of the curve, it can be divided into three stages: elastic stage (oa), the elastic-plastic stage (ab) and the plastic stage (bc or bd). Bc section portrays the stress state of the components which are under axial pressure and Horizontal 
transverse load. Bd section illustrates the components which are only under Horizontal transverse load.

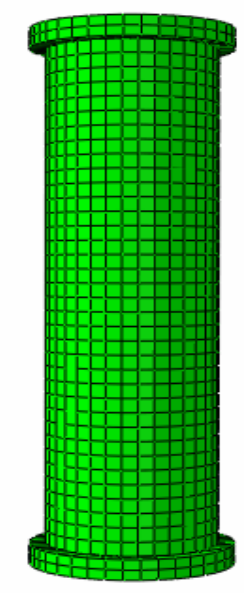

(a)before forced
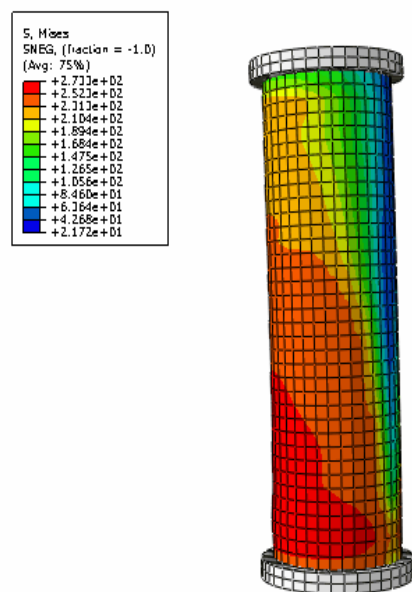

(b)after forced

Fig.1 The state before and after force of composite columns

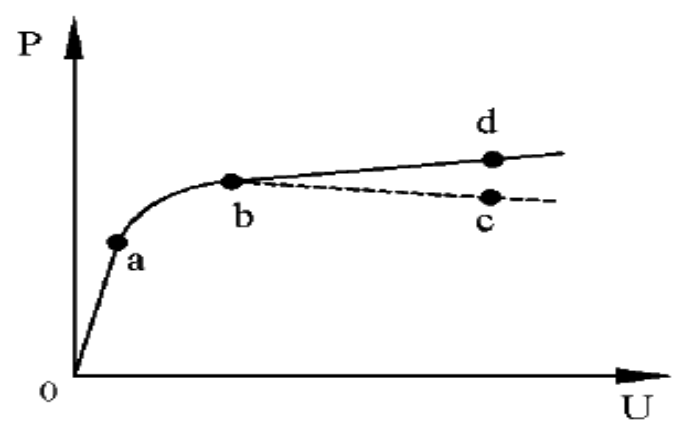

Fig.2 Typical shear component P-U curve

As can be seen from the Fig.2, in the oa elastic stage, P-U curve presents generally rising straight line.The tension zone of the steel tube and concrete section began to appear. Along with the increase of lateral horizontal displacement, the tension zone of the core concrete area also increased gradually. Fig.3, respectively, shows stress distribution nephogram of steel tube, concrete and steel reinforced shear components at point a.
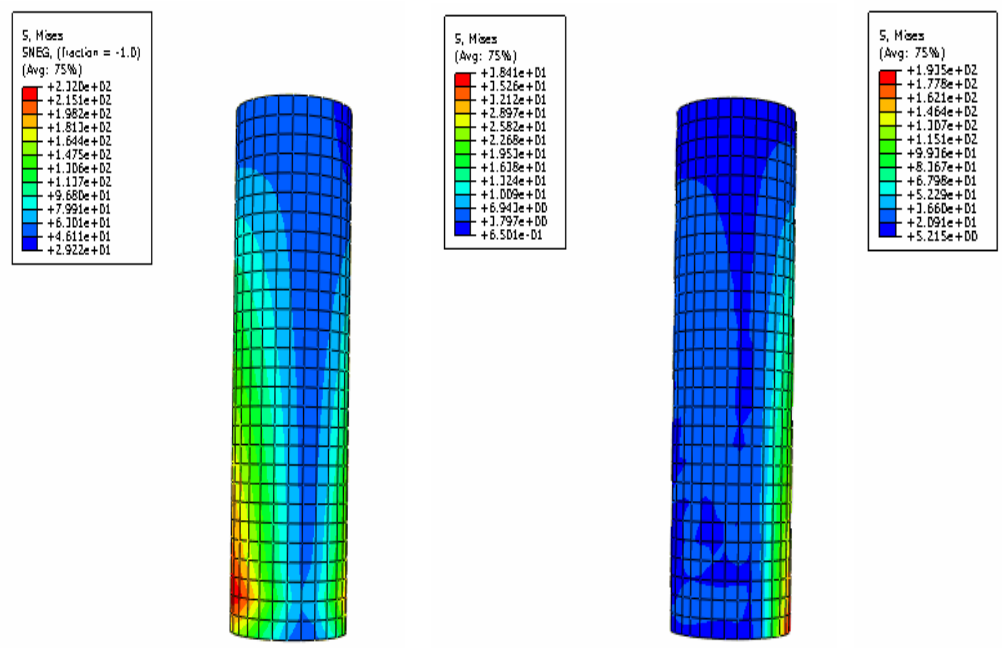

(a)steel tube

(b) concrete

(c)steel-reinforced

Fig.3 Stress distribution of a point 
When entering elastic-plastic stage, $\mathrm{P}$ - $\mathrm{U}$ curve is no longer straight. because of with the increase of the lateral horizontal displacement, the stiffness of composite components continuously decreased, the tension zone of the core concrete and steel reinforced area is constantly increasing, and yield area of steel pipe pressure zone is increasing. When arriving at point $b$, steel tube in tension and compression area has entered the stage of yield. Fig.3, respectively, shows stress distribution nephogram of steel tube, concrete and steel reinforced shear components at point $b$.
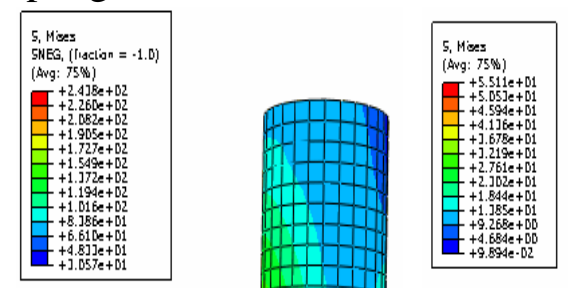

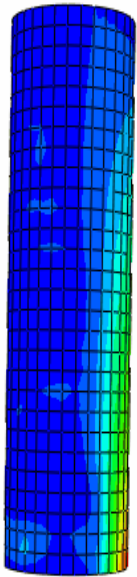

(b)concrete
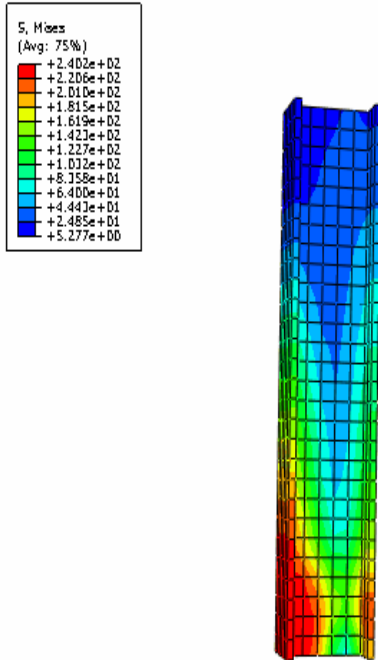

(c)steel-reinforced

(a)steel tube

Fig.4 Stress distribution of $\mathrm{b}$ point

When entering the inelastic phase (bd), P - U curve is close to a straight line, because the stiffness of composite components in elastic-plastic stage has fallen. At point $b$, the stiffness of composite components has hardly dropped. while the tension zone of the core concrete and steel reinforced area is also in constant increase, yield zone of steel pipe pressure area is also increasing. But it still slightly improve the bearing capacity. Fig.4, respectively, shows stress distribution nephogram of steel tube, concrete and steel reinforced shear components in bd section.
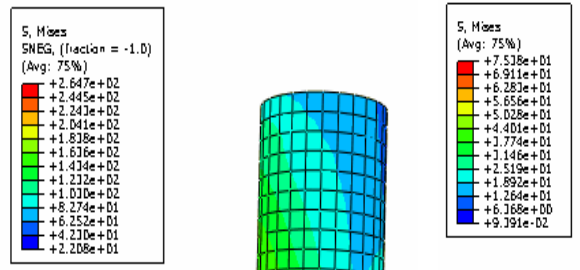

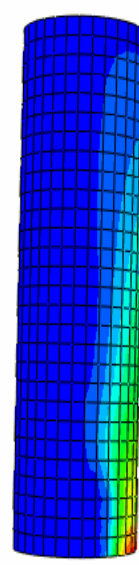

(b)concrete

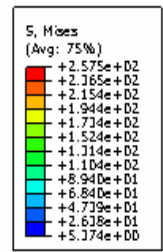

(c)steel-reinforced

(a)steel tube

Fig.5 Stress distribution of $\mathrm{d}$ point

When the steel tube steel reinforced concrete composite components are forced not only stress and transverse load but also the upper horizontal displacement,the vertical load can exert horizontal component which is vertical to the component of vertical axis after deformation. This component can increase the lateral horizontal displacement,which is the so-called $\mathrm{P}-\Delta$ effect.The $\mathrm{P}-\Delta$ effect is slight for the components whose axial compression ratio is small.So the P-U curve tends not to 
exert decline section as shown in the BC. On the contrary it is shown as a reinforcement, as shown in Fig. 1 bd; But for large axial compression ratio components especially the little coefficient of sectional constraints effect ones, the P - $\Delta$ effect is obvious. P - U curve tends to be declined, as shown in the BC section of figure1. Fig.6 shows stress distribution nephogram of steel tube and core concrete and the steel bone for artifacts at point $\mathrm{c}$.

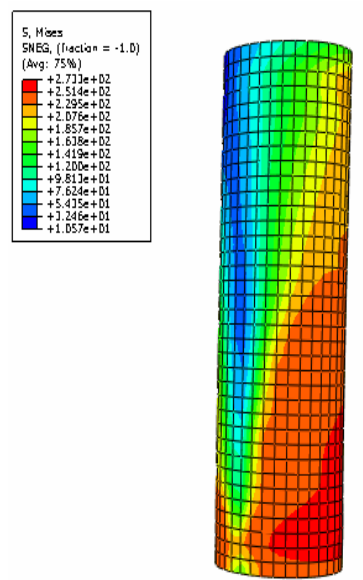

(a)steel tube
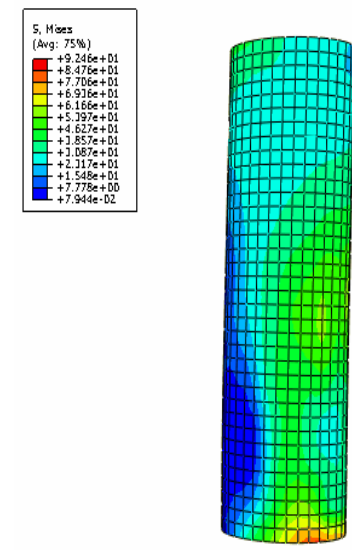

(b)concrete
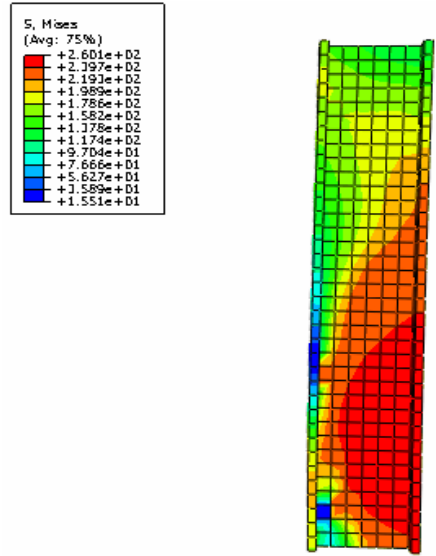

(c)steel-reinforced

Fig.6 Stress distribution of c point

Compared with Fig.6 and Fig.5, you can see the horizontal displacement of Fig.6 obviously is bigger than 5 . The stress of each parts especially for the steel tube and steel bone becomes larger.

\section{Conclusion}

This paper aims to calculate and analyze the property of steel pipe steel reinforced concrete composite column shear components under the effect of lateral horizontal displacement. Using the stress distribution chart of the various components presented when calculating and analysis, we analyzed the working mechanism of steel pipe steel reinforced concrete composite column shear components. It is concluded that the P - $\mathrm{U}$ curve of shear component is divided into three stages: elastic stage, elastic-plastic stage and plastic stage. The main reason is because of influence of the increase of the zone of the steel and concrete compression area. Axial compression ratio has much effect on the plastic stage of the curve. Especially under the condition of high axial compression ratio, the plastic stage exerts the decline section.

\section{Acknowledgement}

It is a project supported by National Science Foundation (51308347) .

It is a project supported by Shenyang Science Plan project (F13-171-9-00).

It is a project supported by Shenyang Science Plan project (F14-028-2-00).

It is a project supported by Shenyang Science Plan project (F14-210-6-00).

It is a project supported by Liaoning Science public research funds(2014004025).

\section{References}

[1]X L ZHAO, R GRZEBIETA, M ELCHALAKANI. Tests of Concrete-Filled Double Skin Circular Hollow Sections[C]. First Inter. Confer. on Steel \& Composite Structures. Pusan, Korea, June, 2001: 283-290.

[2]Han L H, Tao Z, Zhao X L, Concrete-Filled Double Skin (SHS Outer and CHS Inner) Steel Tubular Beam-Columns [J]. Thin-Wall Structures, 2004, 42 (9): 1329-1355.

[3]Zhong Tao, Linhai Han, Hong Huang.The mechanical properties research on eccentric 
compression column of The hollow interlayer steel tube concrete $[\mathrm{J}]$. Journal of civil engineering, 2003, 36(2):33-40.

[4]Lianguang Wang. The theory and calculation of steel and concrete composite structure[M]. Beijing: Science Press, 2005.

[5]Guoliang Bai, Fuhua Qin. The principle and design of steel reinforced concrete[M].Shanghai: Shanghai Science Technology Press, 2000.

[6]Fam A, QieF S, Rizkalla S. Concrete-Filled Steel Tubes Subjected to Axial Compression and Lateral Cyclic Loads[J]. Journal of Structural Engineering, 2004,130(4):631-640.

[7]Linhai Han,Youfu Yang.Modern technology of steel tube concrete[M].Beijing: China Architecture Industry Press, 2004. 